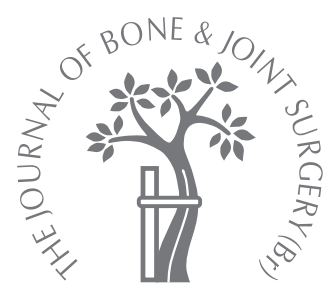

\title{
The impact of tobacco use and body mass index on the length of stay in hospital and the risk of post-operative complications among patients undergoing total hip replacement
}

\author{
O. Sadr Azodi, \\ R. Bellocco, \\ K. Eriksson, \\ J. Adami
}

From Karolinska University Hospital Solna, Stockholm, Sweden
O. Sadr Azodi, MD student, PhD student

In J. Adami, MD, Master of Public Health, PhD, Associate Professor

Department of Medicine, Clinical Epidemiology Unit, Karolinska University Hospital Solna, 17176 Stockholm, Sweden.

R. Bellocco, Sc.D, Professor Department of Medical Epidemiology and Biostatistics Karolinska Institutet, 17177 Stockholm, Sweden and Department of Statistics, University of Milano-Bicocca, 20126 Milan, Italy.

- K. Eriksson, MD, PhD, Orthopaedic Surgeon Department of Orthopaedics Stockholm Söder Hospital, Karolinska Institutet, 11883 Stockholm, Sweden.

Correspondence should be sent to $\mathrm{Dr}$ O. Sadr Azodi; e-mail: sayed-omid.sadrazodi@ki.se

(C)2006 British Editorial Society of Bone and Joint Surgery doi:10.1302/0301-620X.88B10. $17957 \$ 2.00$

$J$ Bone Joint Surg [Br] 2006;88-B:1316-20.

Received 27 March 2006

Accepted after revision 19 June 2006

We carried out a retrospective cohort study of 3309 patients undergoing primary total hip replacement to examine the impact of tobacco use and body mass index on the length of stay in hospital and the risk of short term post-operative complications.

Heavy tobacco use was associated with an increased risk of systemic post-operative complications $(p=0.004$ ). Previous and current smokers had a $43 \%$ and $56 \%$ increased risk of systemic complications, respectively, when compared with non-smokers. In heavy smokers, the risk increased by $121 \%$. A high body mass index was significantly associated with an increased mean length of stay in hospital of between $4.7 \%$ and $7 \%$. The risk of systemic complications was increased by $58 \%$ in the obese. Smoking and body mass index were not significantly related to the development of local complications.

Greater efforts should be taken to reduce the impact of preventable life style factors, such as smoking and high body mass index, on the post-operative course of total hip replacement.

Given the large number of patients who undergo total hip replacement $(\mathrm{THR})^{1}$ it is important both clinically and for public health, to identify those patients who are more susceptible to post-operative complications. We therefore studied the impact of tobacco use and body mass index (BMI) on the post-operative complications following THR and the length of stay in hospital using prospectively collected exposure information from a large, nationwide occupational cohort.

It is widely accepted that smoking is an important risk factor for the development of post-operative complications., 2,3 To our knowledge, the impact of total life-time tobacco smoking and different types of tobacco products on the outcome of THR has not previously been reported.

Similarly, few studies have looked at the impact of BMI on the outcome of THR. ${ }^{4-6}$ Namba et $\mathrm{al}^{5}$ suggested an association between obesity and post-operative wound infection, but their study was based only on univariate analysis and did not consider potential confounding factors.

\section{Patients and Methods}

The Construction Industry's Organisation for Working Environment, Safety and Health (Bygghälsan) was established in 1968 and provided out-patient medical services to construc- tion workers throughout Sweden between 1969 and $1992 .^{7}$ The organisation was a joint venture launched by the trade unions and the corresponding employers associations, which offered preventative health check-ups to all workers in the industry. Data from these check-ups were kept in a central register.

The workers filled in a questionnaire before each visit and to minimise any misunderstanding or inconsistency, the answers were doublechecked by a nurse in the patient's presence. Each worker underwent a mean of three (1 to 9) health check-ups over six to nine years. The questionnaire collected data including a detailed smoking history, anthropometric measurements, and occupation. The quality of the data on smoking has been reviewed and when answers between two and three years apart were compared perfect accordance was found in $89 \% .^{8}$ Figures were missing for $1.3 \%$ of current and $1.4 \%$ of previous smokers and inconsistencies were found in $2.6 \%$ of the smoking data. ${ }^{8}$ There were inconsistencies in the oral snuff data for $7 \%$ of the workers. ${ }^{8}$

The Swedish Inpatient Register stores diagnostic hospital discharge data, ${ }^{9}$ and each record corresponds to one hospital admission and contains up to six discharge diagnoses, coded according to the current International Classification of Disease (ICD). ${ }^{10}$ Patients were identified through their national registration 
numbers which are embedded in each record. The register has been evaluated for validity and completeness, and the codes for the main diagnoses were correct at three-digit level for $92 \%$ to $94 \%$ of the records on surgical patients. ${ }^{11,12}$ For surgical procedures excluding endoscopies or biopsies, the codes were incorrect for $2 \%$ of the records and were missing for $5.3 \% .{ }^{12}$ We were able to follow each patient up to the end of 2002 .

Using the Construction Industry's Organisation for Working Environment and the Swedish Inpatient Register, we identified workers who had undergone elective primary THR for osteoarthritis. We excluded women (because gender could be a possible confounding variable), patients who had undergone a previous THR and those who had their THR as an emergency procedure. We also excluded patients with rheumatoid disease, secondary osteoarthritis, lower extremity fractures, all those who had previous orthopaedic surgical procedures from the lower back to the ankle joint, and those with erroneous personal identification numbers. The final cohort consisted of 3309 male patients.

Two different outcomes were studied; length of stay in hospital and post-operative complications. In order to study the length of stay in hospital, each patient was followed up until the day they returned home. Five patients died in the immediate post-operative period and were excluded from the final analysis. Of the remaining 3304 patients, 3077 (93\%) were discharged home from the hospital in which they underwent their THR, 197 (6\%) were discharged from a second hospital and $30(1 \%)$ returned home after receiving care at more than two hospitals.

Using the Swedish versions of ICD-8 to ICD-10 and the Swedish Classification of Operation and Major Procedures, we recorded the complications that occurred during the first two months after operation. We categorised the complications into local and systemic. The local complications included problems with the prosthesis and those relating to the wound, while systemic complications comprised all others, including death.

The BMI of the patients was divided into three groups according to the World Health Organization (WHO) criteria; normal weight $\left(18.5 \mathrm{~kg} / \mathrm{m}^{2}\right.$ to $\left.24.9 \mathrm{~kg} / \mathrm{m}^{2}\right)$, overweight $\left(25 \mathrm{~kg} / \mathrm{m}^{2}\right.$ to $\left.29.9 \mathrm{~kg} / \mathrm{m}^{2}\right)$ and obese $\left(>30 \mathrm{~kg} / \mathrm{m}^{2}\right)$. No patient was underweight $\left(<18.5 \mathrm{~kg} / \mathrm{m}^{2}\right)$. When assessing the daily amount of tobacco smoked by each patient, cigarettes were assumed to contain $1 \mathrm{~g}$ of tobacco, and cigars 6 g. Pipe smokers reported the amount of tobacco in grams consumed each week. In order to calculate pack years, the total amount of tobacco smoked every day was multiplied by the length of time the patient had been smoking, and divided by 20. Pack years were then divided into four categories (non-smokers, 0 to 19.9 pack years, 20 to 39.9 and $>40$ ). The overall smoking status was categorised as non-smokers, previous, and current smokers. The status of snuff usage was designated as non-users and users. Using ICD-8 to ICD-10, any patient with previous hospitalisation due to myocardial infarction or an acute cerebrovascular event was identified, as were patients with diabetes, congestive heart failure or chronic obstructive lung disease.

Statistical analysis. Descriptive statistics were produced to summarise the length of stay in hospital: natural log transformation was applied to improve its symmetry. Multiple linear regression analysis was used to estimate adjusted associations between length of stay in hospital and BMI and smoking status. The multivariate $\mathrm{F}$ test ${ }^{13}$ was used to assess the significance of each simple variable in the model (a p-value of less than 0.05 was taken to be significant). The overall goodness of fit of the model was studied with the adjusted $\mathrm{R}^{2} \cdot{ }^{13}$ Residual analyses (based on both crude and studentised residuals) were conducted to assess the validity of assumptions in linear regression, and diagnostics analyses were performed to identify possible outliers.

Stratified categorical data analysis and logistic regression modelling were then carried out to study how patients' characteristics could simultaneously affect the likelihood of developing complications within 60 days of surgery. In order to avoid multicollinearity, different tobacco-related exposure factors, such as smoking status, tobacco preference and pack years of tobacco use, were analysed separately and generated different final models. Logistic regression analysis was used to estimate the adjusted oddsratio and its $95 \%$ confidence interval (CI). Stata 9.1 was used to perform the statistical analyses (Stata Statistical Software, College Station, Texas).

\section{Results}

The length of stay in hospital. Details of the cohort in relation to the length of stay in hospital are shown in Table I. The mean age at the time of surgery was 65.6 years (33 to 89). The mean BMI was $26.4 \mathrm{~kg} / \mathrm{m}^{2}$ (18.5 to 43.5 ), with overweight and obese patients accounting for $64.8 \%$ (2142) of the study population. The median length of stay in hospital increased from nine days for patients with a normal BMI to 10 days in the obese group. With regards to the overall smoking status, $38.6 \%$ (1275) of the patients had never smoked, $32.9 \%$ (1087) were current smokers and $28.5 \%$ (942) had smoked previously. The use of snuff $(22.5 \%$; 744$)$ was not as common as smoking. The cohort consisted of $33.1 \%$ (1095) who had never used tobacco in any form, $23.1 \%$ (763) cigarette users, $8.8 \%$ (290) pipe or cigar users, $5.5 \%$ (180) who used snuff exclusively and $27.9 \%$ (922) who used a combination of products. This data was missing for 54 patients $(1.6 \%)$. The median length of stay in hospital did not vary much between patients with different forms of tobacco use. Patients with diabetes, congestive heart failure, chronic obstructive lung disease, or a past history of an acute cerebrovascular or cardiovascular event had a longer stay in hospital.

Multivariate analyses were performed to identify the impact of different tobacco-related variables and BMI on the mean length of stay in hospital. In a multivariate model, increasing BMI was significantly associated with an increased mean length of stay $(p<0.001)$. On a log scale, 
Table I. Characteristics of patients undergoing total hip replacement in relation to the median length of stay in hospital

\begin{tabular}{|c|c|c|c|}
\hline & $\begin{array}{l}\text { Number of } \\
\text { patients }(\%)\end{array}$ & Median & $25^{\text {th }}$ to $75^{\text {th }}$ \\
\hline \multicolumn{4}{|l|}{ Age in yrs } \\
\hline$<55$ & $380(11.5)$ & 9.0 & (7.0 to 11.0$)$ \\
\hline 55 to 59 & $452(13.7)$ & 9.0 & (7.0 to 11.0$)$ \\
\hline 60 to 64 & $592(17.9)$ & 9.0 & (7.0 to 13.0$)$ \\
\hline 65 to 69 & $683(20.7)$ & 10.0 & (8.0 to 14.0$)$ \\
\hline 70 to 74 & $683(20.7)$ & 10.0 & (8.0 to 14.0$)$ \\
\hline 75 to 79 & $352(10.6)$ & 11.0 & (9.0 to 15.0$)$ \\
\hline$>80$ & $162(4.9)$ & 12.0 & (9.0 to 17.0$)$ \\
\hline \multicolumn{4}{|l|}{ Body mass index in $\mathrm{kg} / \mathrm{m}^{2}$} \\
\hline 18.5 to 24.9 (normal) & $1129(34.1)$ & 9.0 & (7.0 to 12.0$)$ \\
\hline 25 to 29.9 (overweight) & $1729(52.3)$ & 10.0 & (8.0 to 14.0$)$ \\
\hline > 30 (obese) & $413(12.6)$ & 10.0 & (8.0 to 14.0$)$ \\
\hline Missing data & $33(1.0)$ & 9.0 & (8.0 to 15.0$)$ \\
\hline \multicolumn{4}{|l|}{ Smoking status } \\
\hline Non-smoker & $1275(38.6)$ & 9.0 & (8.0 to 13.0$)$ \\
\hline Previous & $942(28.5)$ & 10.0 & (8.0 to 14.0$)$ \\
\hline Current & $1087(32.9)$ & 9.0 & (8.0 to 14.0$)$ \\
\hline \multicolumn{4}{|l|}{ Snuff status } \\
\hline Non-user & $2560(77.5)$ & 9.0 & (8.00 to 14.0$)$ \\
\hline User & $744(22.5)$ & 9.0 & (8.00 to 13.0$)$ \\
\hline \multicolumn{4}{|l|}{ Tobacco preferences } \\
\hline None & $1095(33.1)$ & 9.0 & (8.0 to 13.0$)$ \\
\hline Cigarette & $763(23.1)$ & 9.0 & (8.0 to 13.0$)$ \\
\hline Pipe or cigar & $290(8.8)$ & 11.0 & (9.0 to 15.0$)$ \\
\hline Snuff & $180(5.5)$ & 10.0 & (7.0 to 14.0 ) \\
\hline Mixed & $922(27.9)$ & 9.0 & (8.0 to 13.0$)$ \\
\hline Missing data & $54(1.6)$ & 12.0 & (9.0 to 18.0$)$ \\
\hline \multicolumn{4}{|l|}{ Pack years of tobacco use } \\
\hline Non-users & $1275(38.6)$ & 9.0 & (8.0 to 13.0$)$ \\
\hline 0 to 19.9 & $1314(39.8)$ & 9.0 & (8.0 to 14.0$)$ \\
\hline 20 to 39.9 & 438 (13.3) & 10.0 & (8.0 to 14.0$)$ \\
\hline$>40$ & $139(4.2)$ & 10.0 & (8.0 to 15.0$)$ \\
\hline Missing data & $138(4.1)$ & 10.0 & (8.0 to 13.0$)$ \\
\hline \multicolumn{4}{|l|}{ Diabetes } \\
\hline Yes & $107(3.2)$ & 10.0 & (8.0 to 15.0$)$ \\
\hline No & $3197(96.8)$ & 9.0 & (8.0 to 14.0$)$ \\
\hline \multicolumn{4}{|c|}{$\begin{array}{l}\text { Chronic obstructive pulmonary } \\
\text { disease }\end{array}$} \\
\hline Yes & $43(1.3)$ & 11.0 & (9.0 to 18.0$)$ \\
\hline No & $3261(98.7)$ & 9.0 & (8.0 to 14.0 ) \\
\hline \multicolumn{4}{|l|}{ Congestive cardiac failure } \\
\hline Yes & $84(2.5)$ & 12.0 & (9.0 to 17.0$)$ \\
\hline No & $3220(97.5)$ & 9.0 & (8.0 to 14.0$)$ \\
\hline \multicolumn{4}{|c|}{$\begin{array}{l}\text { Previous acute cerebrovascular } \\
\text { event }\end{array}$} \\
\hline Yes & $67(2.0)$ & 10.0 & (8.0 to 14.0 ) \\
\hline No & $3237(98.0)$ & 9.0 & (8.0 to 14.0 ) \\
\hline \multicolumn{4}{|l|}{ Previous myocardial infarction } \\
\hline Yes & $215(6.5)$ & 10.0 & (8.0 to 14.0 ) \\
\hline No & 3089 (93.5) & 9.0 & (8.0 to 14.0 ) \\
\hline
\end{tabular}

after adjustment, the mean length of stay in hospital among overweight and obese patients increased 0.05 and 0.07 respectively when compared with those of normal weight. ${ }^{13}$ On a useful interpretation of $\log$ transformation, ${ }^{13}$ the mean length of stay increased $4.7 \%(95 \%$ CI 2.0 to 7.5$)$ among the overweight group and $7.0 \%(95 \%$ CI 2.9 to 11.1) among the obese group, compared with those of nor-
Table II. Characteristics of patients undergoing total hip replacement in relation to post-operative complications. Patients shown are out of the total number of patients in each group

\begin{tabular}{|c|c|c|c|}
\hline & \multirow{2}{*}{$\begin{array}{l}\text { Total } \\
\text { number of } \\
\text { patients }\end{array}$} & \multicolumn{2}{|c|}{ Number of patients (\%) } \\
\hline & & $\begin{array}{l}\text { Systemic } \\
\text { complications }\end{array}$ & $\begin{array}{l}\text { Local } \\
\text { complications }\end{array}$ \\
\hline Overall rate of complications & 3309 & $268(8.1)$ & 128 (3.9) \\
\hline \multicolumn{4}{|l|}{ Age in yrs } \\
\hline$<55$ & 380 & $20(5.3)$ & $9(2.4)$ \\
\hline 55 to 59 & 452 & $34(7.5)$ & $16(3.5)$ \\
\hline 60 to 64 & 592 & $35(5.9)$ & $18(3.0)$ \\
\hline 65 to 69 & 684 & $49(7.2)$ & $18(2.6)$ \\
\hline 70 to 74 & 685 & $65(9.5)$ & $31(4.5)$ \\
\hline 75 to 79 & 353 & $39(11.1)$ & $20(5.7)$ \\
\hline$>80$ & 163 & $26(16.0)$ & $16(9.8)$ \\
\hline \multicolumn{4}{|l|}{ Body mass index in $\mathrm{kg} / \mathrm{m}^{2}$} \\
\hline 18.5 to 24.9 (normal) & 1129 & $79(7.0)$ & $32(2.8)$ \\
\hline 25 to 29.9 (overweight) & 1731 & $140(8.1)$ & $78(4.5)$ \\
\hline > 30 (obese) & 416 & $45(10.8)$ & $15(3.6)$ \\
\hline Missing data & 33 & $4(12.1)$ & $3(9.1)$ \\
\hline \multicolumn{4}{|l|}{ Smoking status } \\
\hline Non-smoker & 1277 & $83(6.5)$ & $48(3.8)$ \\
\hline Previous & 944 & $89(9.4)$ & $39(4.1)$ \\
\hline Current & 1088 & $96(8.8)$ & $41(3.8)$ \\
\hline \multicolumn{4}{|l|}{ Snuff status } \\
\hline Non-user & 2564 & $217(8.5)$ & $101(3.9)$ \\
\hline User & 745 & $51(6.8)$ & $27(3.6)$ \\
\hline \multicolumn{4}{|l|}{ Tobacco preferences } \\
\hline None & 1096 & $74(6.8)$ & $42(3.8)$ \\
\hline Cigarette & 765 & $70(9.2)$ & $33(4.3)$ \\
\hline Pipe or cigar & 290 & $29(10.0)$ & $11(3.8)$ \\
\hline Snuff & 181 & $9(5.0)$ & $6(3.3)$ \\
\hline Mixed & 923 & $81(8.8)$ & $34(3.7)$ \\
\hline Missing data & 54 & $5(9.2)$ & $2(3.7)$ \\
\hline \multicolumn{4}{|l|}{ Pack years of tobacco use } \\
\hline Non-users & 1277 & $83(6.5)$ & $48(3.8)$ \\
\hline 0 to 19.9 & 1314 & $106(8.1)$ & $53(4.0)$ \\
\hline 20 to 39.9 & 441 & $49(11.1)$ & $15(3.4)$ \\
\hline$>40$ & 139 & $19(13.7)$ & $7(5.0)$ \\
\hline Missing data & 138 & $11(7.9)$ & $5(3.6)$ \\
\hline \multicolumn{4}{|l|}{ Diabetes } \\
\hline Yes & 108 & $10(9.3)$ & $6(5.6)$ \\
\hline No & 3201 & $258(8.1)$ & $122(3.8)$ \\
\hline \multicolumn{4}{|l|}{$\begin{array}{l}\text { Chronic obstructive lung } \\
\text { disease }\end{array}$} \\
\hline Yes & 43 & $2(4.7)$ & $3(7.0)$ \\
\hline No & 3266 & $266(8.1)$ & $125(3.8)$ \\
\hline \multicolumn{4}{|l|}{ Congestive cardiac failure } \\
\hline Yes & 84 & $9(10.7)$ & $10(11.9)$ \\
\hline No & 3225 & $259(8.0)$ & $118(3.7)$ \\
\hline \multicolumn{4}{|l|}{$\begin{array}{l}\text { Previous acute cerebro- } \\
\text { vascular event }\end{array}$} \\
\hline Yes & 67 & $6(9.0)$ & $7(10.5)$ \\
\hline No & 3242 & $262(8.1)$ & $121(3.7)$ \\
\hline \multicolumn{4}{|l|}{ Previous myocardial infarction } \\
\hline Yes & 215 & $21(9.8)$ & $13(6.1)$ \\
\hline No & 3094 & $247(8.0)$ & $115(3.7)$ \\
\hline
\end{tabular}

mal weight. However, there was no statistically significant association between smoking status or tobacco preference and the mean length of stay after adjustment for the other covariates in the model (age, calendar period, BMI, medical region, diabetes, congestive heart failure, chronic obstructive lung disease and a history of previous cerebrovascular or acute myocardial events). 
Post-operative complications. In total, 373 of 3309 patients $(11.3 \%)$ developed one or more post-operative complication. Systemic complications developed in 268 patients, comprising $113(3.4 \%)$ venous thromboembolisms, 44 $(1.3 \%)$ acute cardiac or cerebrovascular events, $69(2.1 \%)$ cases of post-operative anaemia, blood transfusion or gastrointestinal bleeding, 57 cases $(1.7 \%)$ of urinary tract infection or pneumonia and 14 cases $(0.4 \%)$ of death within 60 days. A total of 128 patients developed one or more local complications comprising 89 (2.7\%) prosthesisrelated complications and $41(1.2 \%)$ wound-related complications. The baseline characteristics of patients developing post-operative complications are presented in Table II.

We found a significant increase in the risk of systemic post-operative complications associated with overall smoking status $(\mathrm{p}=0.013)$. When adjusted by multivariate logistic analysis, previous and current smokers had a $43 \%$ (odds ratio (OR) $1.32,95 \%$ CI 1.04 to 1.97 ) and $56 \%$ (OR 1.56, $95 \%$ CI 1.14 to 2.14 ) increased risk respectively of suffering from systemic post-operative complication compared with non-smokers. The preference for different tobacco products was not significant.

A higher number of pack years of tobacco smoking was found to be significantly associated with an increased risk of systemic post-operative complication ( $\mathrm{p}=0.004)$. When adjusted by multivariate logistic analysis, membership of the heaviest tobacco smoking group was associated with a $121 \%$ (OR, 2.21; 95\% CI 1.28 to 3.82 ) increased risk of systemic complications when compared with non-smokers. However, the estimated OR $(1.35 ; 95 \%$ CI 0.99 to 1.84$)$ for those smoking for 0 to 19.9 pack years was not found to be significantly different to that of non-smokers.

There was a tendency for the risk of systemic post-operative complications to rise with increasing BMI $(\mathrm{p}=0.082)$. In the obese group, there was a $58 \%$ (OR, 1.58; 95\% CI 1.06 to 2.35 ) increased risk of systemic post-operative complications compared with those of normal weight.

No statistically significant association was found between smoking status, preference of tobacco product or pack years and local complications.

\section{Discussion}

The results of our study show that tobacco smoking substantially increases the risk of developing systemic postoperative complications. This increase is seen most prominently in the heaviest tobacco smokers, with a risk that is twice as high as that for those who have never smoked. A previous study ${ }^{2}$ on patients undergoing hip and knee replacement showed that any history of smoking increased the risk of overall post-operative complications. Our study has the advantage of using prospectively-collected information on tobacco exposure and is based on a very large sample size. Furthermore, it is able to highlight the impact of the total life-time dose of tobacco on the outcome of THR. Although the Swedish Inpatient Register gives a very accurate main discharge diagnosis, we are aware that the data on secondary discharge diagnoses could be incomplete or misclassified. ${ }^{14}$ However, it is reasonable to assume that misclassifications or missing data occurring in this registry are evenly spread across all types of smoker. ${ }^{15}$

Of particular interest is the estimated increased risk of systemic post-operative complications due to a high BMI. Previous studies have shown that obesity is associated with an increase in the incidence of post-operative complications among patients undergoing procedures such as solid pancreas organ transplantation, ${ }^{16}$ prostatectomy ${ }^{17}$ and radical cystectomy. $^{18}$

Smokers and the obese are prone to chronic systemic diseases. ${ }^{19-22}$ Poor health may make these patients more susceptible to systemic complications. The incidence of postoperative complications after knee or hip replacement is substantially reduced if patients stop smoking before surgery. $^{23}$

In this study, there was no significant association between smoking status and the incidence of local complications. Previous studies have shown an increased risk of wound-related complications among smokers. ${ }^{24}$ Relatively few of our patients developed these $(1.2 \%)$. We are aware that wound-related complications may be under-reported. ${ }^{25}$ Furthermore, detection of factors affecting the survival of the prosthesis need longer follow-up periods. Therefore, our analysis of tobacco status on local complications may lack the statistical power to detect a significant difference in rates of complication between the different groups.

There was no correlation between the median length of stay in hospital and smoking status. This is consistent with the results of previous studies of patients undergoing orthopaedic operations. $^{2,23}$ Our findings could, in part, be explained by the minimal variation in the median length of stay in hospital between the different tobacco status groups. We were not able to detect any statistically significant difference between these groups.

Patients with high BMI seemed to spend up to $7 \%$ longer in hospital. This may increase the costs to the health care system.

Our findings show that smoking and obesity substantially increase the risk of systemic complications after THR. Greater attention should be paid to these factors when preparing patients for surgery.

\section{Supplementary Material}

$\because$ Supplementary tables showing the statistical analysis of changes in the length of stay in hospital according to smoking status and body mass index are available with the electronic version of this article on our website at www.jbjs.org.uk

We wish to express our particular thanks to Dr David Lindström and Dr Andreas Wladis for their valuable comments. Furthermore, we thank the Olle Engkvist Byggmästare Foundation for funding a scholarship for the primary author which made it possible to perform this investigation.

No benefits have been received or will be received from a commercial party related directly or indirectly to the subject of this article. 


\section{References}

1. Herberts P, Malchau H, Garellick G. Annual Report 2003. The Swedish Hip Arthroplasty Register. www.jru.orthop.gu.se [accessed 27 March 2006].

2. Moller AM, Pedersen T, Villebro N, Munksgaard A. Effect of smoking on early complications after elective orthopaedic surgery. J Bone Joint Surg [Br] 2003;85-B: 178-81.

3. Bluman LG, Mosca L, Newman N, Simon DG. Preoperative smoking habits and postoperative pulmonary complications. Chest 1998;113:883-9.

4. Ibrahim T, Hobson S, Beiri A, Esler C. No influence of body mass index on early outcome following total hip arthroplasty. Int Orthop 2005;29:359-61.

5. Namba RS, Paxton L, Fithian DC, Stone ML. Obesity and perioperative morbidity in total hip and total knee arthroplasty patients. J Arthroplasty 2005;20(7 Suppl): 46-50.

6. Ridgeway S, Wilson J, Charlet A, et al. Infection of the surgical site after arthroplasty of the hip. J Bone Joint Surg [Br] 2005;87-B:844-50.

7. Engholm G, Englund A, Fletcher AC, Hallin N. Respiratory cancer incidence in Swedish construction workers exposed to man-made mineral fibres and asbestos. Ann Occup Hyg 1987;31:663-75.

8. Nyrén 0, Bergström R, Nyström L, et al. Smoking and colorectal cancer: a 20-year follow-up study of Swedish construction workers. J Natl Cancer Inst 1996;88:1302-7.

9. Hansson LE, Nyren 0, Hsing AW, et al. The risk of stomach cancer in patients with gastric or duodenal ulcer disease. N Engl J Med 1996;335:242-9.

10. World Health Organization. International Statistical Classification of Disease and Related Health Problems, 10th Revision. Version for 2006. http://www3.who.int/icd/ currentversion/fricd.htm (accessed 12/08/06).

11. Naessen T, Parker R, Persson I, Zack M, Adami HO. Time trends in incidence rates of first hip fracture in the Uppsala Health Care Region, Sweden, 1965-1983. Am J Epidemiol 1989;130:289-99.

12. Nilsson AC, Spetz CL, Carsjo K, Nightingale R, Smedby B. Reliability of the Hospital Registry: the diagnostic data are better than their reputation. Lakartidningen 1994;91:598, $603-5$ (in Swedish).
13. Vittinghoff E, Glidden DV, Shiboski SC, McCulloch CE. Regression methods in biostatistics: linear, logistic, survival and repeated measures models. New York: Springer Verlag, 2005:32.

14. Gunnarsson U, Seligsohn E, Jestin P, Påhlman L. Registration and validity of surgical complications in colorectal cancer surgery. Br J Surg 2003;90:454-9.

15. Rothman KJ, Greenland S. Modern epidemiology. Second Ed. Lippincott, Williams \& Wilkins, 1998:127-32

16. Hanish SI, Petersen RP, Collins BH, et al. Obesity predicts increased overall complications following pancreas transplantion. Transplant Proc 2005;37:3564-6.

17. Ahlering TE, Eichel L, Edwards R, Skarecky DW. Impact of obesity on clinical outcomes in robotic prostatectomy. Urology 2005;65:740-4.

18. Lee CT, Dunn RL, Chen BT, et al. Impact of body mass index on radical cystectomy. J Urol 2004;172:1281-5.

19. Sturm R. The effects of obesity, smoking, and drinking on medical problems and costs. Health Aff 2002:21:245-53.

20. Reynolds K, He J. Epidemiology of the metabolic syndrome. Am J Med Sci 2005: 330:273-9.

21. Foy CG, Bell RA, Farmer DF, Goff DC Jr, Wagenknecht E. Smoking and incidence of diabetes among U.S adults: findings from the Insulin Resistance Atherosclerosis Study. Diabetes Care 2005;28:2501-7.

22. McCaughan F, Spiro SG. Management of patients with COPD. Lancet 2004;364: 2015

23. Moller AM, Villebro N, Pedersen T, Tonnesen H. Effect of preoperative smoking intervention on postoperative complications: a randomised clinical trial. The Lancet 2002:359:114-17.

24. Finan KR, Vick CC, Kiefe CI, Neumayer L, Hawn MT. Predictors of wound infection in ventral hernia repair. Am J Surg 2005;190:676-81.

25. No authors listed. Cancer Incidence in Sweden 2003. National Board of Health and Welfare. Centre of Epidemiology. 